Kateřina Chadimová

Jana Cahlíková

Lubomír Cingl

\title{
Foretelling What Makes People Pay: Predicting the Results of Field Experiments on TV Fee Enforcement
}

Max Planck Institute for Tax Law and Public Finance Working Paper 2019 - 15

September 2019

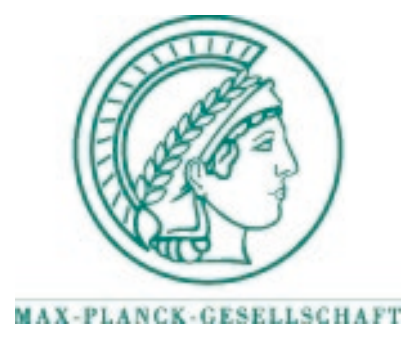

Max Planck Institute for Tax Law and Public Finance

Department of Business and Tax Law

Department of Public Economics

http://www.tax.mpg.de 
Working papers of the Max Planck Institute for Tax Law and Public Finance Research Paper Series serve to disseminate the research results of work in progress prior to publication to encourage the exchange of ideas and academic debate. Inclusion of a paper in the Research Paper Series does not constitute publication and should not limit publication in any other venue. The preprints published by the Max Planck Institute for Tax Law and Public Finance represent the views of the respective author(s) and not of the Institute as a whole. Copyright remains with the author(s).

Max Planck Institute for Tax Law and Public Finance

Marstallplatz 1

D-80539 Munich

Tel: $\quad+498924246-0$

Fax: $\quad+498924246-501$

E-mail: ssrn@tax.mpg.de

http://www.tax.mpg.de 


\title{
Foretelling What Makes People Pay: Predicting the Results of Field Experiments on TV Fee Enforcement
}

\author{
Kateřina Chadimová ${ }^{1}$, Jana Cahlíková ${ }^{\&}$ Lubomír Cingl $^{3}$ \\ ${ }^{1}$ Institute of Economic Studies, Faculty of Social Sciences, Charles University in Prague, Czech Republic \\ e-mail: kchadimova@gmail.com \\ ${ }^{2}$ Department of Public Economics, Max Planck Institute for Tax Law and Public Finance, Munich, Germany \\ e-mail: jana.cahlikova@tax.mpg.de \\ ${ }^{3}$ Department of Economics, Faculty of Economics, University of Economics in Prague, Czech Republic \\ e-mail: lubomir.cingl@vse.cz
}

September 19, 2019

\begin{abstract}
One of the current challenges in field experimentation is creating an efficient design including individual treatments. Ideally, a pilot should be run in advance, but when a pilot is not feasible, any information about the effectiveness of potential treatments' to researchers is highly valuable. We run a laboratory experiment in which we forecast results of two largescale field experiments focused on TV license fee collection to evaluate the extent to which it is possible to predict field experiment results using a non-expert subject pool. Our main result is that forecasters were relatively conservative regarding the absolute effectiveness of the treatments, but in most cases they correctly predicted the relative effectiveness. Our results suggest that, despite the artificiality of laboratory environments, forecasts generated there may provide valuable estimates of the effectiveness of treatments.
\end{abstract}

Keywords: lab experiments, forecasting experimental results, field experiments, behavioral economics

JEL: C91, C92, C93, D03

Acknowledgement and funding: We would like to express our gratitude to Julie Chytilová for her review and comments. All errors remaining in this text are the responsibility of the authors. The research was supported by GA UK grant No. 1372519 and by the Czech Science Foundation Grant P402/19/15943S. 


\section{Introduction}

Field experiments in both public and private sectors are currently experiencing rapid development, as cooperation between economists and institutions is relevant for both sides; careful application of insights from behavioral economics can significantly improve a firm's effectiveness or nudge hesitating people to act, whilst economists are given unique opportunities to test various theories under realistic settings. However, large field experiments are typically complex to carry out, as they require demanding preparation including close cooperation of the experiment's partners, and treatments can carry significant costs. Indeed, proper and efficient design of field experiments presents ongoing challenges in a fast-paced world in which time is precious and experimenters are often under pressure to deliver results quickly, especially when they are cooperating with profit-oriented private entities.

A cornerstone of experimental design lies in the individual treatments. However, it may often be unclear whether the treatments are designed in a sufficiently powerful way, as existing evidence may be nontransferable due to, e.g., a specific institutional setting, local environment or subject pool. In order to address this, pilot programs are often used to pretest the experimental design and evaluate treatment effectiveness. However, it is not always possible to run a pilot, especially in situations in which subjects' behavior is affected by previous experience with the treatments, or, generally whenever the experimenters are given only one opportunity to conduct the study.

One possible channel to evaluate treatment effectiveness ex-ante is simply to ask other people to predict the results of the field experiments. DellaVigna and Pope (2018a) run an experiment with an online subject sample, and show that valuable information can be obtained even from a nonexpert sample pool. While expert forecasters (i.e. behavioral economists, standard economists, and psychologists) made better predictions than non-experts (i.e. undergraduates, MBAs, and the online sample on MTurk), non-experts were equally accurate when asked to predict the rank

order of the treatments. Moreover, DellaVigna and Pope (2018a) found a strong wisdom-of-crowds effect, as the average group forecast outperforms $96 \%$ of individual treatments.

Building on a work by DellaVigna and Pope (2018a), we run a laboratory experiment in which we forecast results of two large-scale field experiments focused on television license fee collection; an experiment by Fellner et al. (2013) conducted in Austria in 2005 and our own field study Cahlíková et al. 2019) conducted in the Czech Republic in 2017. We collect and analyze forecasts made by non-experts, a student subject pool $(\mathrm{N}=93)$. Our main result is that students were relatively conservative when predicting the absolute effectiveness of the treatments, but they correctly predicted their relative effectiveness. Our research suggests that it is possible to gain valuable information about the design of an experiment even in a simple lab environment, including obtaining early estimates of the effectiveness of individual treatments and thus to minimize potential unnecessary expenses.

Despite its artificiality, a laboratory environment has several advantages that can be highly beneficial to experimental economists. First, a laboratory is a familiar and easily controlled site for experimenters. This may be especially important when evaluating treatments that are confidential from the general public, when online sample respondents cannot be used. In a lab, the experimenter knows the identity of all subjects and can ensure that subjects will comply with informed consent preventing information leakage. Second, student subject pools are typically easy and quick to 
recruit. This is in sharp contrast to collecting data from geographically dispersed experts or busy managers.

To our knowledge, this is the first study aimed at predicting the results of a large natural field experiment in the context of a real institutional setting of tax enforcement. The result of the laboratory survey constitutes new evidence in the small but growing literature on forecasts of economic research results, which have mainly been focused on effort task experiments. Several existing studies report rather mixed evidence of predictability, as the results are dependent on the definition of accuracy measures, number of forecasters (i.e., sample size), or the level of expertise of the forecasters. Erev et al. (2010) is one of the first examples of predicting experimental results, organizing three choice prediction competitions and using learning models trained on data. In contrast, DellaVigna and Pope (2017) are more interested in whether academic experts are able to make quick and intuitive forecasts, as are often made in informal consulting and discussions. They compare the results of a large-scale real-effort experiment with eighteen treatment arms to forecasts by 208 academic experts, and conclude that, on average, the experts successfully anticipated the effect of psychological motivators. In their follow-up study, DellaVigna and Pope (2018a) compare the accuracy of predictions made by experts and non-experts, confirming the predictability of effort task research results even by non-experts when accuracy is defined as rank-ordering treatments. Heinz et al. 2017) report remarkable aggregate accuracy of HR managers' predictions of worker productivity in a field experiment on the productivity response when employers treated co-workers unfairly. Coffman and Niehaus (2014) collect predictions from persuasion research in the context of a buyer-seller relationship. Samek and Longfield (2019) conducted an incentivized survey in which fundraising experts and the general public expected substantial effect of treatment in experiment on charitable giving, while there was actually no effect in the field. To examine whether the effect of a soft skills training program on employment could be anticipated, Groh et al. (2016) elicit estimates from the audience of a research presentation and an online readers' sample. Bloom et al. (2018) complement their analysis of a long-term effect of change in management practices in several weaving firms with predictions by consulting experts. Other examples of forecasting experimental results can be found in Sanders et al. (2015) and DellaVigna and Pope (2018b).

Our study is also closely related to the literature on prediction markets, where market price might serve as an indicator of the probability of certain events (e.g. Wolfers and Zitzewitz 2004 Wolfers and Zitzewitz 2006; Snowberg et al. 2007) and it is specifically related to work on beliefs about the reproducibility of scientific research. In this strand of literature, prediction markets are used to predict the outcomes of replications, constituting important evidence on the current debate about the lack of reproducibility of statistically significant results (Dreber et al. 2015, Camerer et al. 2016; Forsell et al. 2018).

This paper is organized as follows. In Section 2 we describe in detail the two field experiments that we predict; in Section 3 we present the design of the laboratory experiment in which we collected the actual predictions made by a student sample pool. Section 4 summarizes and discusses the results and Section 5 concludes. 


\section{$2 \quad$ Field Experiments}

\subsection{Motivation \& Institutional Background}

As their main source of revenues, the collection of taxes and fees constitutes an important topic for public sector entities, which provide a variety of key services. Efficient collection of revenues can be especially challenging in settings in which a payer is asked to self-report information for the payment. In the specific cases of Austria and the Czech Republic, each household that owns a TV is obliged by law to register and pay a monthly fe $\varrho^{1}$ for national public television broadcasting. However, an enforcement problem arises, as the households are required to self-register, though the public broadcasting is freely accessible to anyone regardless of fee payment.

The traditional economic approach to the improvement of tax and fees collections relies on the insight that a rational taxpayer has incentives to avoid the taxes as long as the expected gains from evasion exceed the costs of detection (Allingham and Sandmo, 1972). As a result, the recommended way to address the issue of non-compliance is to strengthen the enforcement process and increase the probability of detection (improved monitoring, higher fines, prosecution, etc.). However, such measures are often limited by law, costly to implement, and in many cases it is questionable whether they really pay off. Behavioral economics considers the induction of behavioral changes that could produce similar effects as traditional measures, but at markedly lower expense. Several studies on tax and fee collection have shown that the manner in which certain information is presented by mail can generate meaningful effects compared to traditional approaches (Slemrod, 2018).

The Austrian license fee system is managed by "Fee Info Service" (Gebüher Info Service, GIS), a subsidiary of the Austrian public broadcasting company. The main task of GIS is to enforce and collect TV license fees. GIS mails notices regularly throughout the year to potential evaders with information about their liability to pay the fees and how to register and start paying. To identify residents who will potentially evade payment, GIS maintains its own database, which is compared to residence data. Households that have not registered a TV are treated as potential evaders. Once this group of interest is reached via letter, the License Fee Act requires those recipients to respond and to provide truthful information on why they do not pay license fees. Therefore, the variable of interest is not only the number of households which register in response to the mailings, but also the number of households that respond to the letter to clarify their situation. A standard GIS mailing to potential license fee evaders consists of a cover letter, an information sheet and a response and registration form with a postage prepaid envelope. The cover letter notifies the recipient that since she has not registered a TV, she is suspected of fee evasion and is obliged to clarify her situation by responding within two weeks. The information sheet contains selected parts of the License Fee Act, information about the payment duty, amount of the fee and a description of legal consequences in case of detection of avoidance (Fellner et al. 2013 ).

The situation is very similar in the Czech Republic, where the public broadcasting service Czech Television (CT) itself is responsible for TV fees collection and corresponding mailing campaigns. By law, all households owning a TV receiver are obliged to self-register and pay a monthly license fee (135 CZK, €5.20). Again, an enforcement problem arises since the public broadcasting is freely

${ }^{1}$ In 2005 , the amount of annual fees ranged from $€ 206-263$, depending on the particular federal state in Austria (Fellner et al. 2013). In 2016, the amount of annual fee was approximately $€ 60$ in the Czech Republic. 
accessible. By law, CT can identify potential evaders by comparing electricity data to residence data, and, consequently, can send a letter requesting clarification.

\subsection{Field Experiment: Czech Republic}

\subsubsection{Experimental Design}

The large-scale natural field experiment was conducted in the Czech Republic in May/June 2017 in cooperation with Czech Television (Cahlíková et al. 2019) $)^{2}$. We modified the original letter used in previous mailing campaigns (O1, "original letter"), creating six new text versions focused on testing different motives for non-compliance (T1-6). The new letters were sent through CT to randomly chosen $95 \%$ of the subject sample $(N=82,645)$, along with one of the three envelope variants in an orthogonal design, further stratified by age and ZIP code.

First, by substantially simplifying the "original letter" O1, we created a "control letter" T1, which served as a baseline treatment (Figures 5 6 6 in the Appendix). Second, to test for different motives underlying tax compliance, we added and varied one paragraph into the control letter, creating five various treatments, T2-6. In the "participation" treatment (T2) we asked recipients to express their preferences about CT productions in an online web-based survey to stimulate the feeling of having control over how their fees are spent ${ }^{3}$. The "why" treatment (T3) explains the main reason TV is financed through license fees and several advantages of this system are presented. Specifically, the importance of autonomous means of financing for independent public broadcasting is highlighted, reflecting recent concerns regarding independent media's position in the local context. The "deterrence" (T4) treatment mentions possible consequences of not paying license fees, as the broadcaster is obliged by law to prosecute a non-payer and to assume that a non-response is an active decision to evade the fees, thereby including the omission-andcommission principle. Possible financial sanctions can amount to up to 10,000 CZK (€388) and other legal steps can be taken. However, we did not include amounts in the text. On the CT request, the precise wording had to be carefully formulated to avoid severe negative reactions from disgruntled recipients, so the last sentence claims that the CT does not want to impose penalties unless forced. The "exchange" treatment (T5) mediates a business-like interaction between the $\mathrm{CT}$ and the respondent, focusing on reciprocity, i.e. what services and productions are provided in exchange for the fees. The exchange (T5) is almost identical to the participation (T2) treatment except for the headline and the last sentence where the link to a web page that presents random interesting facts about CT and its production is included instead of the survey. The "social norm" (T6) treatment informs respondents that many households actually pay the fees (9 out of 10) and the non-payers are therefore in a clear minority. The treatment might persuade hesitant households to register on the license fee database by stating that "It is normal to pay".

\footnotetext{
${ }^{2}$ Here we present only the main aspects of the field experiment which are relevant for understanding the prediction of the lab experiment. The design and results of the field study will be described in detail in Cahlíková et al. (2019).

${ }^{3}$ The survey included three questions: the first question was the selection of three types of agenda the respondents would like to see more often out of a menu of ten choices. In the second question respondents were asked to choose three particular shows. The third question was a selection of other CT products that the respondent uses from a menu of four choices.
} 


\section{Participation (T2)}

"Which programs would you like to watch? The CT broadcasts over 110 hours of programs daily on its six channels. Two thirds are produced by the CT, including all-day news, children's shows (Bedtime Story), serials (Rapl, Martin the Doctor), co-produced shows (the Angel of Glory 2, the Theory of Tiger), sports events (World Hockey Championship, EURO 2016, Summer Olympic Games), and high-quality entertainment shows (StarDance). Tell us which types of programs are the most important to you at www.ceskatelevize.cz/mujnazor."

\section{Why (T3)}

"Why do TV license fees exist? Television license fees ensure that there is an independent public broadcaster in the Czech Republic that supports domestic television and film production, and provides the public with balanced news and other services. The TV fees represent a stable source of funding for $\mathrm{CT}$ and account for $90 \%$ of its revenue. Additionally, the number of commercials on CT is limited by law. Thanks to the fees, the $\mathrm{CT}$ is not dependent on income from the state budget or private sources."

\section{Deterrence (T4)}

"What are the possible consequences of not responding? If you do not answer this call within 30 days, CT will be forced to assume, on the basis of the Act on TV and radio license fees (348/2005 Coll., §9, par. 1), that you are obliged to pay the fees, but you choose not to. In this case, you can face a fine and may have to pay all fees retroactively. However, CT does not want to apply this option unless necessary."

\section{Exchange (T5)}

"What do you receive in exchange for your fees? The CT broadcasts over 110 hours of programs daily on its six channels. Two thirds are produced by the CT, including all-day news, children's shows (Bedtime Story), serials (Rapl, Martin the Doctor), co-produced movies (the Angel of Glory 2, the Theory of Tiger), sports events (the World Hockey Championship, EURO 2016, Summer Olympic Games), and high-quality entertainment shows (StarDance). Do you want to know more about the activities of the CT? Visit www.malokdovi.cz."

\section{Social norm (T6)}

"It is normal to pay. Nine out of ten households in the Czech Republic pay the television license fees as required by law. Why should your household be an exception? If you have a TV set at home, but you do not pay the fees, you are in the group of "free riders", for whom the honest households have to pay." 


\subsubsection{Results}

The results of the field experiment are presented in Figure 1. Out of 4,133 addresses included in the T0 control group that did not receive an email, only three households contacted CT $(0.073 \%)$ in the 90 days after the last batch of mail, and two of those registered $(0.048 \%)$. The households, therefore, do not act if they are not contacted by $\mathrm{CT}$.

The control letter (T1), on the contrary, generated a sizable response rate of $57.6 \%$, from the delivered letters, which is clearly a significant difference $(p<0.000$, two-sided test of equality of proportions). The only treatment that generated a larger response rate is the deterrence (T4) $(p<0.000)$, which increased the response rate by 8.5 percentage points, while other treatments (T2-3,5-6) do not differ from the baseline (all $p^{\prime} s>0.36$ ).

The same effect is also observable in registration rates, as the control letter (T1) generated a $20.8 \%$ registration rate out of all delivered mail. The deterrence treatment (T5) was even more effective, leading to a $25.1 \%$ registration rate $(p=0.000)$ whilst the rest of the treatments (T2$3,5-6)$ were not different from the control letter (T1) in term of registration rate (all $p^{\prime} s>0.393$ ).

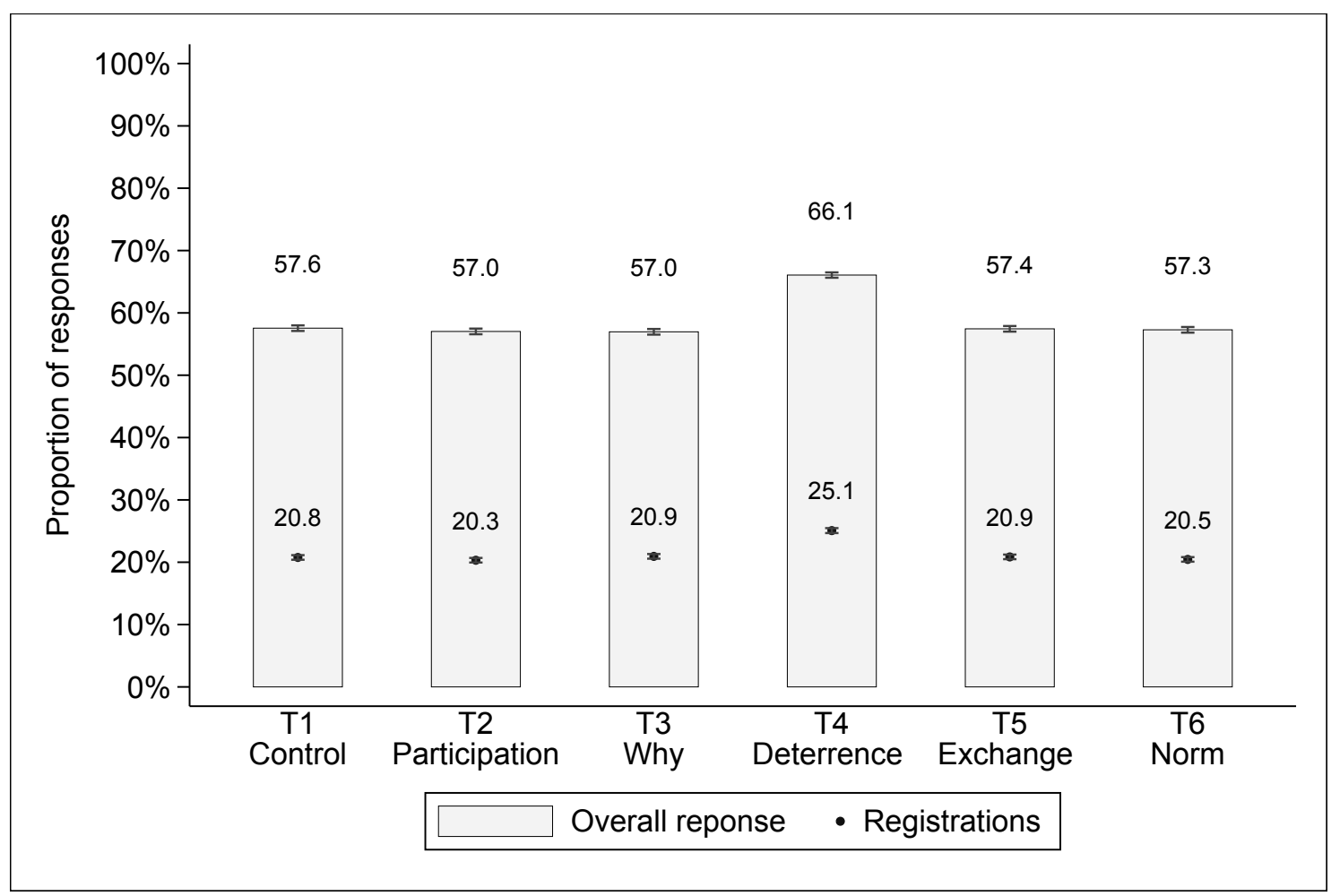

Figure 1: Mailing response and registration rates within 90 days (means with $95 \%$ confidence intervals). Percentages are relative to the number of delivered mailings. 


\subsection{Field Experiment: Austria}

\subsubsection{Experimental Design}

For the purposes of the experiment, Fellner et al. (2013) modified the text of the original cover letter sent by the GIS (hereafter referred to as "the letter" for brevity), while everything else (the response form and the info sheet) remained the same. Naturally, the authors also created a control group (A0) which did not receive a letter in order to construct a relevant counterpart to the mailing schemes. All in all, the experimenters sent letters to 50,498 potential evaders in two waves during September and October 2005.

First, as a baseline (A1), Fellner et al. (2013) use the standard letter that GIS sent in their previous mailing campaigns (Figures 7 in the Appendix). Second, the authors present five text variants of the baseline letter that differ in that one or two paragraphs contain different information, which addressed several distinct motives (or combinations) of non-compliance to payment of TV license fees. The five information treatments reflect the most probable reasons for avoidance of fee payment. The first variant (labeled "threat", A2) warns the recipients what may happen if they are found to have violated the law, by pointing out GIS' standard enforcement practice. The second variant ("social information", A3) appeals to the social norm of compliance and provides information about the actual level of tax fee compliance. The third variant of the letter ("moral appeal", A5) incorporates a moral appeal and points out that compliance is ethically correct. The other two treatments are then combinations of the independent treatments with the threat ("threat x info", A4 \& "threat x moral", A6).

\section{Threat (A2)}

"If you do not respond to this letter, a staff member of GIS will contact you in order to request information from you personally. If you refuse to provide information or if there is a well-founded suspicion that you provide disinformation, GIS is obligated to order an inquiry by the responsible federal authorities. Please keep in mind that in this case you may face legal consequences and considerable costs."

\section{Social information (A3)}

"Do you actually know that almost all citizens comply with this legal duty? In fact, 94\% - a vast majority of all households - have registered their broadcasting receivers."

\section{Moral appeal (A5)}

"Those who do not conscientiously register their broadcasting receivers not only violate the law, but also harm all honest households. Hence, registering is also a matter of fairness."

\subsubsection{Results}

The following section summarizes the results of the mailing treatments A1-A6, including the number of registrations, updates, and the overall response relative to the number of delivered letters. Importantly, only $0.31 \%$ of individuals registered for license fees in the control group 
(A0), which did not receive a letter. Further, there are substantial differences in the effectiveness of the individual treatments (Figure 2). Concerning the response rate, the threat manipulation (A2) generated the highest number of responses. The authors find a significant positive effect of the threat (A1 vs. A2, $p=0.024$, A3 vs. A4, $p=0.014$ and A5 vs. A6, $p=0.000$ ). Further, they indicate negative effects from the social information (A1 vs. A3, $p=0.005$ and A2 vs. A4, $p=0.008$ ) and the moral appeal (A1 vs. A5, $p=0.000$ and A2 vs. A6, $p=0.010$ ). Therefore, the "threat" variant (A2) represents the only manipulation that is more effective than the baseline variant of the letter. Similarly, the authors find a significant positive effect on the registration rate of the threat manipulation between treatments A1 and A2 $(p=0.034), \mathrm{A} 3$ and A4 $(p=0.003)$ and between A5 and A6 $(p=0.020)$. On the other hand, no significant effects are detected between social information and baseline (A3 vs. A1, $p=0.420$ ) and between moral appeal and baseline (A5 vs. A1, $p=0.369$ ). The same trend is observable when the two treatments are interacted with the threat (A4 vs. A2, $p=0.948$ and A6 vs. A2, $p=0.493$ ) (Fellner et al., 2013).

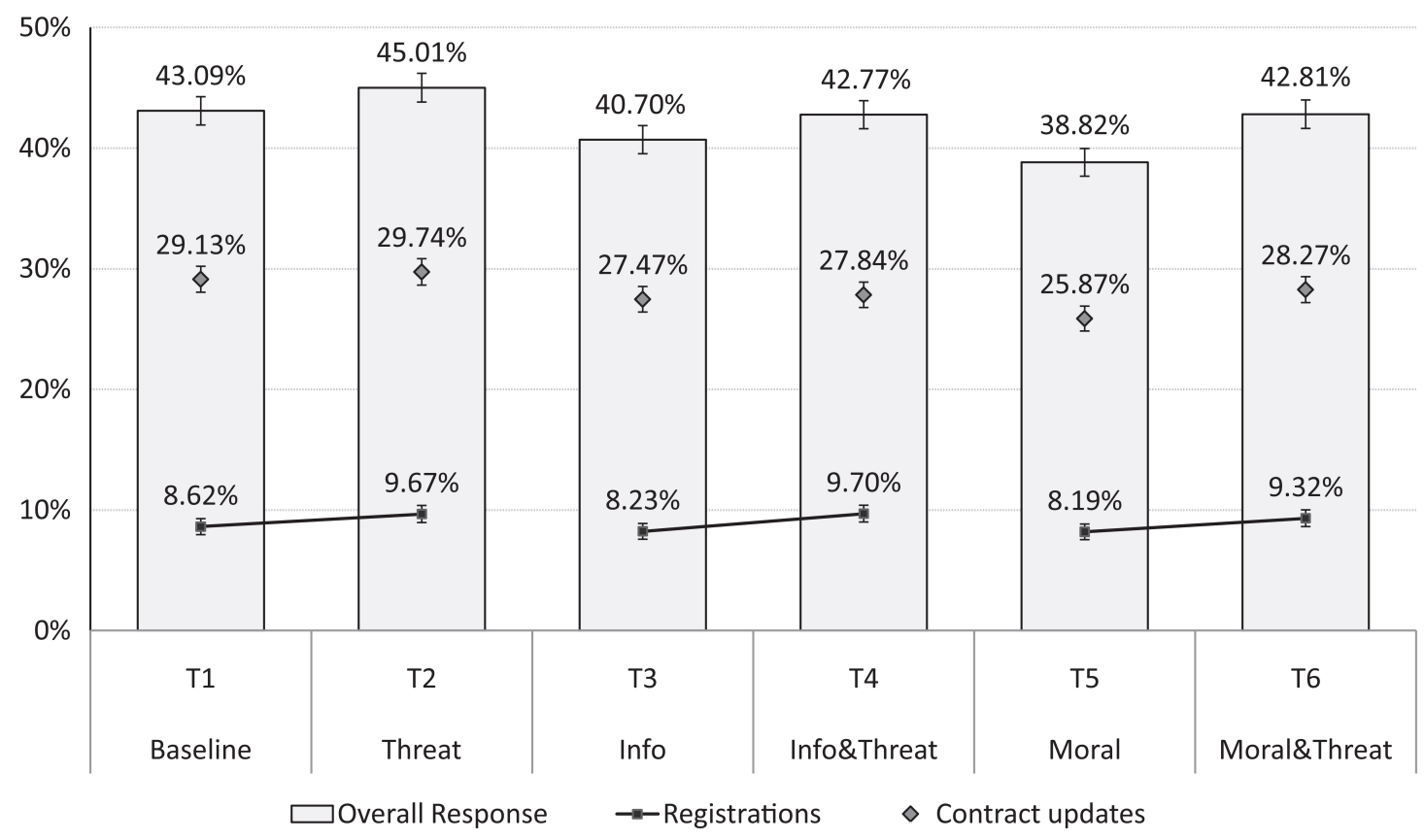

Figure 2: Mailing response within 50 days (means with $95 \%$ confidence intervals). Percentages are relative to the number of delivered mailings (Fellner et al. 2013). For better clarity, we renamed treatments T1-6, using A1-6 throughout the current paper. 


\section{Laboratory Experiment}

We conducted a computerized laboratory experiment 4 to test the extent to which it is possible to forecast field experiment results in a lab. Participants in the experiment (mainly university students) made their own predictions of the effects of the letter treatments used in the field experiments in Austria and in the Czech Republic. The experiment took place at the Laboratory of Experimental Economics (LEE) at the University of Economics in Prague, Czech Republic, and consisted of six experimental sessions. The treatments followed the treatments in the field experiment, being implemented in a within-subject design. Importantly, subject's decisions did not interact with each other and were not restricted by time limits.

\subsection{Power Calculations}

We conducted power calculations to determine the ideal sample size for the forecasting lab experiment. A sample smaller than statistically required increases the probability of mistakenly concluding that there will be no effect of the evaluated intervention. We used G*Power, a power analysis program for statistical tests commonly used in social and behavioral research (Faul et al. 2007). Nevertheless, as noted in Duflo et al. (2007), power calculations in practice involve substantial guess work, as one must have a prior idea of the mean and the variance of the outcome. Since our data are not normally distributed, we used a nonparametric Wilcoxon-Mann-Whitney test. We wish to achieve standard statistical power $80 \%$ with a significance level $\alpha=0.05$ and a minimum effect size to which the test is sufficiently sensitive $d=0.42$ expecting mean group 1 (2) in letter forecasts (based on the Fellner et al. (2013) results) equal to 44 (43) and $S D \sigma$ group 1 (2) equal to 2.50 (2.25)). According to Cohen (2013) this effect size is classified as small to medium. Altogether, with these parameters, we need to have at least 93 subjects predicting the effectiveness of each treatment to achieve $80 \%$ statistical power.

\subsection{Sample Description \& Payment Procedure}

We collected data from 93 participants in total. All participants were students; undergraduates $(59.6 \%)$, graduates with a bachelor's degree $(25.5 \%)$, and master's degree holders $(12.8 \%)$. Their median age was 23 and their most common field of study was economics and finance (42.5\%). The experiment was conducted in the Czech language, and we recruited only subjects with Czech nationality to ensure they were familiar with the local institutional setting.

Participants were recruited using the online recruitment system ORSEE (Greiner, 2015) and were paid privately approximately 3 months from the experimental sessions, based on the accuracy of their predictions. At the end of each session, we randomly selected one of the two field experiment:5 to calculate rewards. Because the lab experiment took place before the field experiment with CT, we postponed the payments until the results from the field were obtained. The average payment was 350 CZK (app. €13.6), including a guaranteed show-up fee of 150 CZK (app. €5.8), and each experimental session lasted approximately 1 hour and 40 minutes.

In order to elicit a participant's beliefs about a probabilistic event, we calculated their rewards according to the quadratic scoring rule (QSR), one of a family of so-called proper scoring rules

\footnotetext{
${ }^{4}$ The experiment was programmed and conducted with the Z-TREE software Fischbacher $(2007)$.

${ }^{5}$ Either the one from Austria run by Fellner et al. (2013) or our own field experiment Cahliková et al. (2019).
} 
(Winkler and Murphy, 1968). Since the participant reports a prediction about a future event, the specific score employed is equal to max $-\mid$ pred - real $\left.\right|^{2} \alpha$, where $\max$ is the maximum amount that the participant could earn, real is the actual effect of the letter and $\alpha$ is a sensitivity parameter. Therefore, the more accurate a prediction, the more money paid to the participant. Nevertheless, the QSR maximizes a participant's expected utility only if she is risk-neutral. Under risk aversion, the marginal utility of the monetary payment to the participant confounds the effect of her beliefs, complicating belief elicitation.

\subsection{Task: Making Predictions}

The participants performed a simple task designed in a similar way as in DellaVigna and Pope (2018a), i.e. making forecasts about field experiment results. In order to be able to forecast treatment effectiveness, subjects had to be familiar with the institutional context and how mailing campaigns were organized. In order to ensure that all of them had exactly the same information we distributed a brief summary in a folder and also read it aloud. Subjects kept the folder throughout the whole experiment so that they could go back to any information if needed. Thus, the subjects became familiar with the system of financing public service television, i.e. how the potential evaders are addressed via mailings and that they are obliged to respond to the letters and clarify their situation with regard to license fees. Consequently, there were two variables of interest:

- the total number of answers, i.e. whether a recipient's household responded to the letter, meaning that any type of response was counted (e.g. update of contact details, filing a claim of possession of no $\mathrm{TV}$, registration into the database, etc.)

- the total number of registrations, i.e. whether a recipient's household newly registered for regular payment of the TV license fees

In order to avoid possible confusion, we emphasized that the total number of answers clarifying the situations of the recipients also included the registrations and therefore, it had to always be higher than or equal to the total number of registration:

Once the subjects were familiar with the institutional context, they had time to read carefully all the letters used in the field experiments sent by GIS (Austria) and by CT (Czech Republic) before the prediction task began. To make the work with letters easier, we printed them out, organized them into a compact fil 7 and marked them with a label, stating the particular variant of the mailing (i.e. T1-6 and A1-6). Moreover, the manipulated paragraphs were highlighted for the purpose of the lab experiment. Afterwards, participants were asked to read a description that appeared on the monitor screen introducing the task:

"In this part of the experiment, your task will be to predict what percent of households will respond to the mailing and what percent of households will register in a license fee database as a reaction to the letter."

After reading the instructions, the subjects proceeded to a trial stage in which they could try to control the program in order to make predictions and test how much money they would receive

\footnotetext{
${ }^{6}$ This was also technically addressed in z-TREE.

${ }^{7}$ The letters were included in the same folder as the institutional setting summary.
} 
depending on the accuracy of their prediction 8 . The subjects were also informed that at the end of the experiment, one of their predictions would be chosen at random and the payment would be calculated based on this particular prediction. This setting is incentive compatible, as the participants pay attention to all predictions equally. Once everything was clear, the subjects proceeded to the main part of the experiment, shown in Figure 98 in the Appendix.

In the main stage, the participants were asked to make forecasts of the effectiveness of the different letters using movable sliders. In order to provide a relevant benchmark, the results of the baseline treatment (A1; Austria) and the original letter (O1; Czech Republic) were displayed at the top of the screen, using a fixed slider 9 . In order to make the forecasting task as transparent as possible, we incorporated the following features:

i) To mitigate possible confusion and inconsistency of predictions, all the sliders (for both response and registrations rates) were presented on the same screen (Figure 986.

ii) Although the benchmark results were displayed in absolute numbers, the subjects made predictions relative to the baseline treatment.

iii) Importantly, we limited the scale in the sliders to relative effects between -10 and 10 percentage points.

There were three sequential rounds of forecasting in total - two rounds for the Czech Republic and one for Austria. First, the subjects made forecasts about treatment effectiveness in the Czech Republic (first round). Second, they made the forecasts for Austria. After that, the actual results of the Austrian field experiment were presented on the computer screen and subjects were asked to adjust their forecasts for the Czech Republic from the first round if they wanted to (second round).

\footnotetext{
${ }^{8}$ For more detail on how we calculated payoff, see Section 3.2

${ }^{9}$ In the Austrian experiment, the experimenters used the original letter sent by GIS as a baseline version (T1). Therefore, the actual effect of the baseline T1 was presented to the subjects in a lab on a computer screen using a fixed slider, to facilitate forecasts for treatments T2-6, as the experiment was forecast ex-post. In contrast, as the results of the Czech field experiment were forecast ex-ante, it was not possible to provide the same information as in the Austrian part. Therefore, we used the response and registration rates from the previous mailing campaign organized by CT itself in 2014, leading to $38 \%$ responses and $5.1 \%$ registrations out of all delivered mailings. Therefore, in the Czech part of the experiment, subjects were asked to make a first prediction of the absolute effectiveness of the new baseline version T1 (based on the information from 2014, i.e. old baseline) and then to make forecasts about the effectiveness of the T2-6 treatment relative to the T1 baseline version.
} 


\section{Results}

\subsection{Czech Republic}

The results of the first and second round of forecasting are summarized in Figure 3 and Table 1 . In the first round of predictions, participants expect a new baseline letter (control, T1) to be more effective in terms of elicited responses compared to the original letter from 2014 (O1) by 6.4 percentage points, as the average forecast response rate was $44.8 \%(\mathrm{SE}=0.9)$ vs. $38.0 \%$. Although the original letter $(\mathrm{O} 1)$ was not directly tested in randomized control trial against other treatments T1-6, forecasters perceive the simplified design of the control letter (T1) to be substantially more effective than the original letter (O1) by about $18 \% 10$

Importantly, only the detterence (T4) treatment is perceived to be more effective than the control T1, by 3.7 p.p., with a predicted response rate of $48.5 \%(p=0.001$; Wilcoxon rank sum test for two samples). All other treatments (T2-3,5-6) do not statistically differ from the control T1 (all $p$-values $>0.258$ ). The predictions are always slightly higher than the control, but the differences are small (below 0.91 p.p. in all cases). The same trend applies to forecasts of registration rate. The new baseline letter (control, T1) is predicted to be more effective by 2.7 p.p. (i.e. increase of $56 \%)$ than the letter used in the past (O1) $(p=0.000,7.7 \%$ predicted with $\mathrm{SE}=0.6$ vs. $5.1 \%$ registration rate). Deterrence T4 is expected to be the most powerful text variant to increase the number of registrations, as the average forecast of its effectiveness is $10.0 \%$ (i.e. $30 \%$ more than control T1, $p=0.000)$, while the average forecasts for the other treatments $(\mathrm{T} 2-3,5-6)$ do not differ from the control T1 (all $p$-values $>0.322$ ).

We did not detect any difference in forecasts by students of economics or finance and others. Although the other group is more optimistic about the effectiveness of all treatments in absolute terms (app. 1.5-2.0 p.p. more in response rate and 0.8-1.0 p.p. more in registration rate), the difference is not statistically significant. Additionally, we find a moderate wisdom-of-crowds effect when prediction accuracy is defined as the absolute error, as summarized in Table 3 . In other words, the mean absolute error of predictions is lower than $64.5-73.1 \%$ of individual absolute errors based on a particular treatment.

The results in the $2^{\text {nd }}$ round are obviously affected by the results of the Austrian field experiment, as all forecast rates are lower (Figure 3). Nevertheless, the deterrence T4 treatment is still seen as the only treatment more effective than the control T1 when examining the overall response rate $(p=0.003, p>0.706$ for all the other treatments $\mathrm{T} 1 \mathrm{vs.} \mathrm{T} 2-3,5)$. In contrast, social norm T6 is perceived as the only treatment less effective than control T1 at this stage, as the average forecast response rate is lower by 1.1 p.p. $(p=0.058)$. Naturally, social norm T6 is also regarded as the least effective treatment among T3-6, as the average forecast response rate is $42.7 \%$ ( $p$-values $<0.043$ for T6 vs. T3-5 and $p=0.061$ for T6 vs. T2). Similar findings also apply to the registration rate, where the deterrence $\mathrm{T} 4$ is again expected to be the only treatment more effective than the control T1 ( $p=0.283, p>0.283$ for all the other treatments). Again, we did not report any statistically significant difference between the students of economics or finance and others. Similarly to the $1^{\text {st }}$ round, mean absolute forecasting error is lower than $67.7-73.1 \%$

\footnotetext{
${ }^{10}$ This result is also supported by a short questionnaire in which we asked students to compare letters $\mathrm{O} 1$ and $\mathrm{T} 1$ : $\mathrm{T} 1$ is shorter (99\% of all forecasters, $\mathrm{N}=93)$, more comprehensive $(77 \%)$, clearer $(97 \%)$, subjects have a better idea what they are asked to do by CT $(76 \%)$, and they have stronger motivation to act ( $84 \%)$.
} 
of individual errors, suggesting the persistence of a mild wisdom-of-crowds effect (Table 3).

Interestingly, the forecasts of the Czech field experiment in Figure 3 exhibit exactly the same pattern as the actual results of the field experiment (Figure 11). Thus, qualitatively, the students correctly predicted that the only efficient treatment would be the deterrence (T4) and that all versions would perform better than the letter used in the prior mailing campaigns. However, this does not apply to their absolute accuracy, as the true effect of the forecast treatments is substantially underestimated. We suggest that this might be driven by the nature of the task itself, as the students were first asked to guess the absolute effectiveness of the control letter (T1), having information about the original letter (O1). Information on the effectiveness of T1, if it were provided ex-ante, would certainly be more useful for forecasters; however, the data were still to be collected at the time. In many cases, predicting results in absolute terms is a very challenging task even for experts. Another question is whether the results of the Austrian field study comprise relevant information for forecasting on the Czech field study. Although the predictions were not substantially changed in the second round, the results from the first round were more accurate, so the forecasters predicted better without information on the Austrian experiment results.

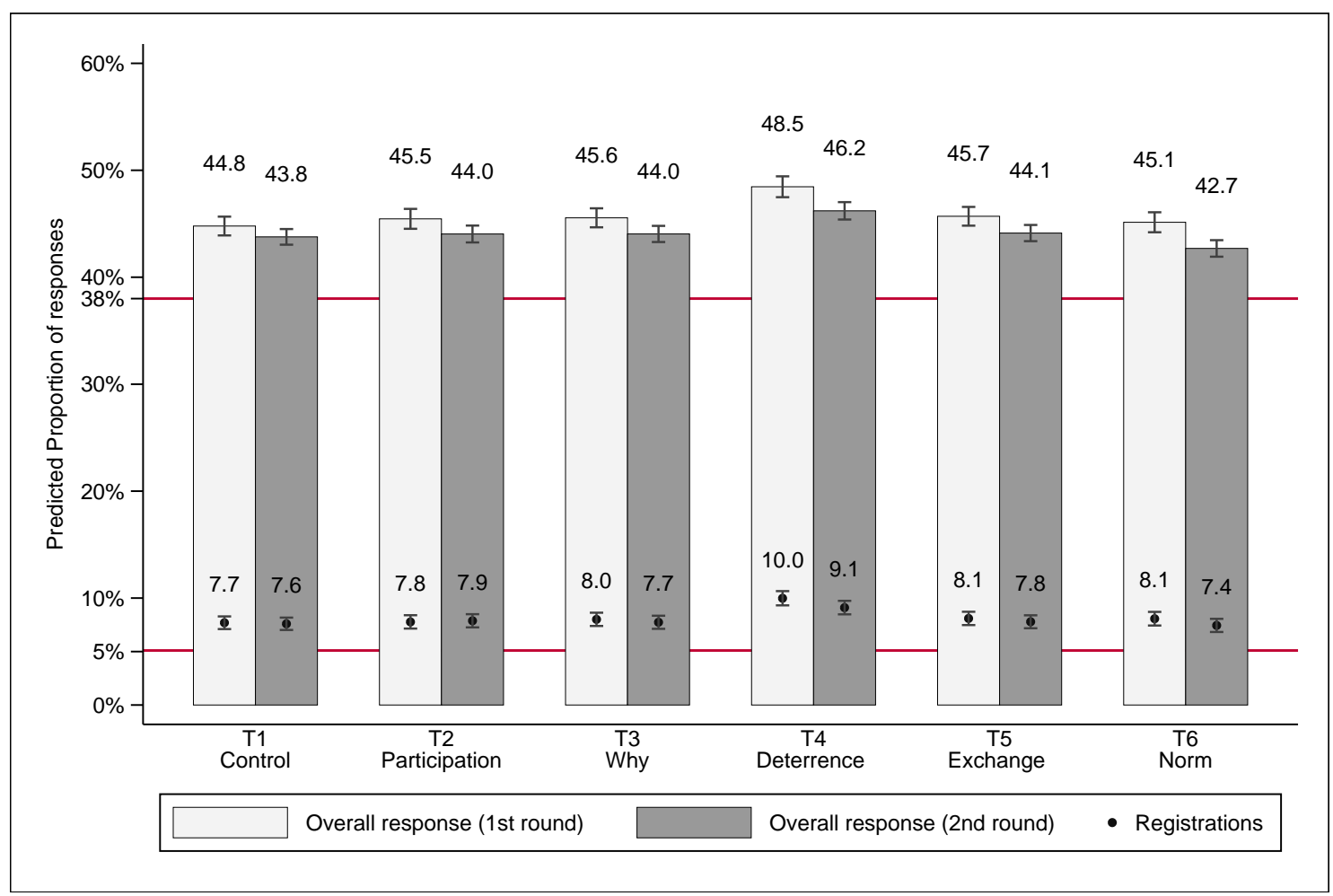

Figure 3: Forecast results - Czech Republic (means with 95\% confidence intervals). Percentages are relative to the number of mailings delivered. Horizontal lines indicate response and registration rates of the original letter $(\mathrm{O} 1)$, presented to the subjects as benchmark. 


\subsection{Austria}

The results of the Austrian round of forecasting are summarized in Figure 4 . The subjects expect a baseline letter A1 to be the least effective in terms of elicited responses compared to the other versions (A2-6) by 1.0-2.8 p.p., as the average forecast response rate was $43.1 \%$ vs. $44.1-45.9 \%$ based on the particular treatment. Although the predicted differences are rather subtle, they are statistically significant at 0.01 significance level using Wilcoxon signed rank test for one sample (all $p$-values $<0.000$ ). Obviously, the statistical significance of results is driven by the very small $\mathrm{SD}$ of forecasts. Further, adding the threat into the letter is correctly anticipated to increase the response rate (A1,3,5 vs. A2,4,6; all $p$-values $<0.000$; Wilcoxon signed rank test for one sample and Wilcoxon rank sum test for two samples). Interestingly, for social info and moral treatments, the forecasters expect positive effects only when they are added in the baseline version of the letter (A1 vs. A3,5) while no effect is expected when they are added in the threat letter (A2 vs. A4,6; all $p$-values $>0.586$ ). Although Fellner et al. (2013) detect a significant negative effect of social info (A2 vs. A4) and moral appeal (A2 vs. A6), we find no statistically significant difference between these forecasts, demonstrating that the forecasters consider all three treatments equally effective. All in all, forecasts of A1 vs. A3,5 go in the opposite direction from the field experiment where info A3 and moral A5 treatments perform worse compared to the baseline A1.

Similarly, when analyzing registration predictions, the baseline letter A1 was expected to be the least effective compared to the other versions (A2-6) by 0.4-1.7 p.p., as the average forecast registration rate was $8.6 \%$ vs. $9.0-10.3 \%$ based on the particular treatment (all $p$-values $<0.000$ ). Forecasters expect a positive effect of adding the threat (A1,3,5 vs. A2,4,6; all $p$-values $<0.000$ ). The social info A3 and moral appeal A5 treatments are expected to increase the registration rate only when added to the baseline (A1). Therefore, the relative trends for the registration rate forecasts are similar to the response rate, suggesting certain consistency in predictions. Nevertheless, Fellner et al. (2013) find no significant effect of social info and moral appeal (see Section 4.3) for registration rate. Thus, our forecasters wrongly predict an effect $(\mathrm{A} 3,5)$ compared to the baseline (A1).

Finally, we did not find any difference in forecasts of response and registration rates by the students of economics or finance and others. We detected a moderate wisdom-of-crowds effect, as the mean absolute forecasting error of the registration rate is lower than more than $50 \%$ of

individual errors (Table 44). Concerning the overall response rate, the wisdom-of-crowds effect is present only in some treatments.

The forecasters perform worse on the Austrian experiment than on the Czech one. Although forecasters correctly anticipate a positive effect of adding the threat paragraph in the letters, they wrongly expect treatments A2-6 to be more effective than the baseline A1. This is at odds with the findings of Fellner et al. (2013), where adding paragraphs with social or moral motivation has a negative effect on response rates and no effect on registration rates (A1 vs. A3,5). 


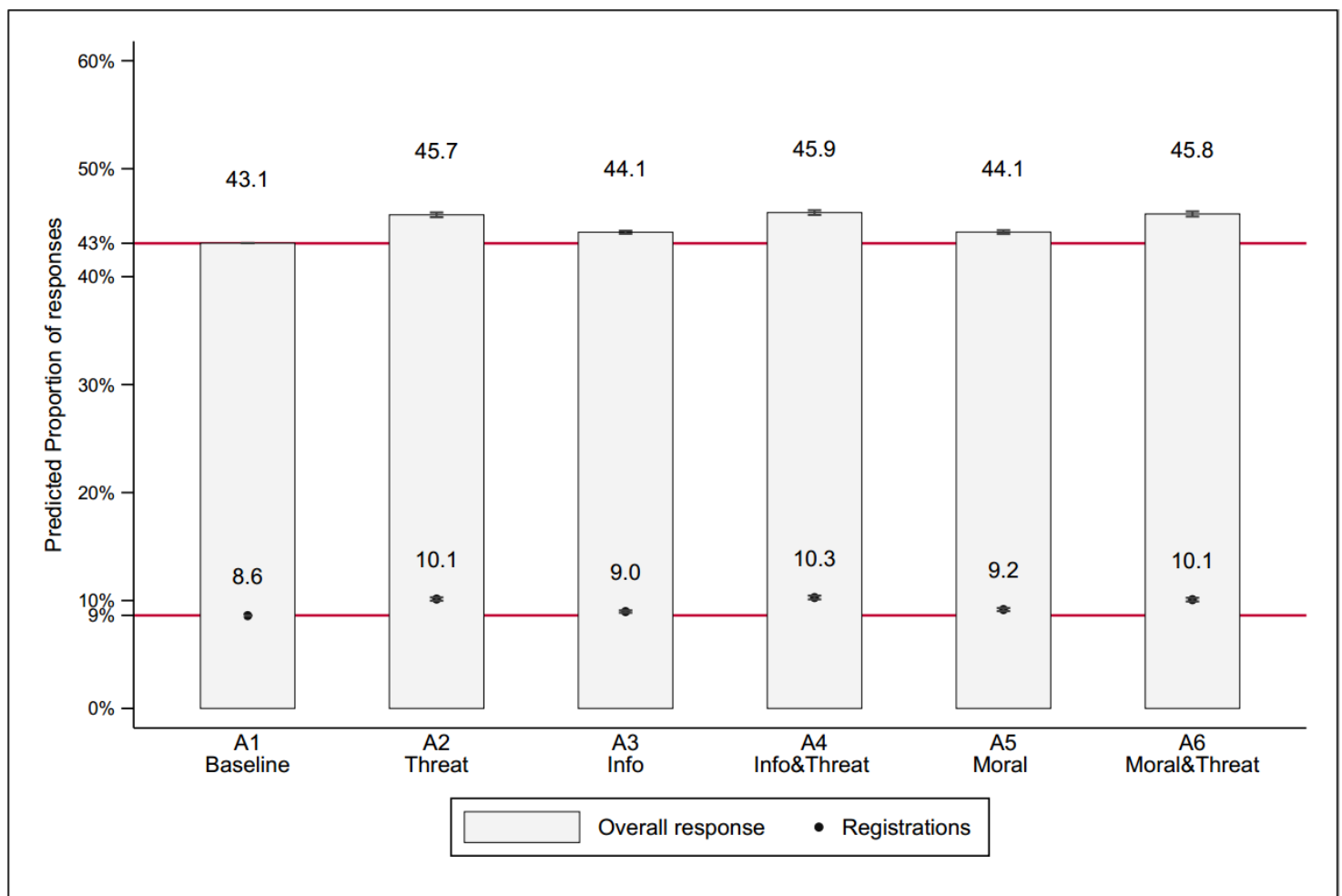

Figure 4: Forecast results - Austria (means with 95\% confidence intervals). Percentages are relative to the number of mailings delivered. Horizontal lines indicate response and registration rates of the baseline letter (A1), presented to the subjects as benchmark. 


\section{Conclusion}

This paper contributes to the literature on forecasting research results. We run a laboratory experiment with a student subject pool to study whether it is possible to collect relevant forecasts from non-experts. Subjects predict results of two large-scale field experiments that investigate underlying motives for non-compliance in TV license fee collection, using an experiment by Fellner et al. (2013) conducted in Austria in 2005 and our own field study (Cahlíková et al., 2019) conducted in the Czech Republic in 2017. Both field experiments are designed as mailing campaigns, utilizing several textual versions of letters, each investigating a specific behavioral channel for noncompliance. The variables forecast in the lab are identical to the main variables of interest in the field studies: response rate (total number of answers relative to delivered mailings, i.e. whether a recipient's household responded to the letter, meaning that any type of response was taken into account) and registration rate (total number of registrations relative the delivered mailings, i.e. whether a recipient's household newly registered for regular payment of the TV license fees).

Individual forecasts are elicited in the same manner as in DellaVigna and Pope (2018a), as subjects are first given information about the effectiveness of a baseline version of the letter (i.e. baseline A1 for Austria and original letter O1 for the Czech Republic) and subsequently asked to predict the relative effectiveness of the treatments (A2-6 for Austria and T1-T6 for the Czech Republic) ${ }^{11}$. For the Czech field experiment, our main result is that students were relatively more conservative with their predictions than the actual results (absolute effectiveness of the treatments), but they correctly predicted the magnitude of individual treatments (relative effectiveness of the treatments). In other words, the forecasts capture a strong effect of emphasizing the consequences of TV fee evasion (deterrence treatment) and suggest a relatively minor influence of behavioral framing. Importantly, this is exactly the same trend as was detected in the field study. When predicting results of the Austrian field experiment, forecasters again correctly anticipated a positive effect of the threat treatment. However, they were not successful in comparing effectiveness of the other treatments to the baseline letter, as their forecasts go in the opposite direction from the field study. Our study suggests that, to some extent, it is possible to gain valuable information about experimental design ex-ante even in a simple lab environment, obtaining early estimates of the effectiveness of individual treatments and thereby to minimize potential unnecessary expenses associated with inefficient treatments.

Our results suggest that, despite the natural artificiality of laboratory environments, forecasts generated there can provide valuable insights into the design of many field experiments. Yet, many questions remained unanswered, calling for further research. First, future work could incorporate the general population in terms of relevant representative samples for the domain of interest. Speaking about TV license fee and public taxes in general, it might be valuable to compare predictions made by student subject pools, academic experts and, as the target population, households. Second, as current evidence is mixed, it might be worthwhile to scrutinize the question of the generalizability of prediction experiments and define areas in which they may be most effective. Finally, we suggest forecasting the efficiency of other behavioral channels than those discussed in this paper, extending the current evidence on predictability of tax enforcement treatments.

\footnotetext{
${ }^{11}$ For details of the design of the laboratory experiment, see Section 3.3
} 


\section{References}

Michael. G. Allingham and Agnar Sandmo. Income tax evasion: A theoretical analysis. Journal of public economics, 1(3-4):323-338, 1972.

Nicholas Bloom, Aprajit Mahajan, David J. McKenzie, and Donald John Roberts. Do Management Interventions Last? Evidence from India. World Bank Policy Research Working Paper No. 8339, 2018.

Jana Cahlíková, Kateřina Chadimová, Lubomír Cingl, and Miroslav Zajíček. Carrots or Sticks? Field Evidence on What Makes People Pay TV Fees. Working paper. Unpublished, 2019.

Colin F. Camerer, Anna Dreber, Eskil Forsell, Teck-Hua Ho, Jürgen Huber, Magnus Johannesson, Michael Kirchler, Johan Almenberg, Adam Altmejd, Taizan Chan, et al. Evaluating replicability of laboratory experiments in economics. Science, 351(6280):1433-1436, 2016.

Lucas Coffman and Paul Niehaus. Pathways of persuasion. Working paper, 2014.

Jacob Cohen. Statistical power analysis for the behavioral sciences. Routledge, 2013.

Stefano DellaVigna and Devin Pope. What motivates effort? Evidence and expert forecasts. The Review of Economic Studies, 85(2):1029-1069, 2017.

Stefano DellaVigna and Devin Pope. Predicting Experimental Results: Who Knows What? Journal of Political Economy, 126(6):2410-2456, 2018a.

Stefano DellaVigna and Devin Pope. Stability of Experimental Results: Forecasts and Evidence. Working Paper, 2018b.

Anna Dreber, Thomas Pfeiffer, Johan Almenberg, Siri Isaksson, Brad Wilson, Yiling Chen, Brian A Nosek, and Magnus Johannesson. Using prediction markets to estimate the reproducibility of scientific research. Proceedings of the National Academy of Sciences, 112(50): 15343-15347, 2015.

Esther Duflo, Rachel Glennerster, and Michael Kremer. Using randomization in development economics research: A toolkit. Handbook of development economics, 4:3895-3962, 2007.

Ido Erev, Eyal Ert, Alvin E Roth, Ernan Haruvy, Stefan M. Herzog, Robin Hau, Ralph Hertwig, Terrence Stewart, Robert West, and Christian Lebiere. A choice prediction competition: Choices from experience and from description. Journal of Behavioral Decision Making, 23(1):15-47, 2010.

Franz Faul, Edgar Erdfelder, Albert-Georg Lang, and Axel Buchner. G* power 3: A flexible statistical power analysis program for the social, behavioral, and biomedical sciences. Behavior research methods, 39(2):175-191, 2007.

Gerlinde Fellner, Rupert Sausgruber, and Christian Traxler. Testing enforcement strategies in the field: Threat, moral appeal and social information. Journal of the European Economic Association, 11(3):634-660, 2013. 
Urs Fischbacher. z-tree: Zurich toolbox for ready-made economic experiments. Experimental economics, 10(2):171-178, 2007.

Eskil Forsell, Domenico Viganola, Thomas Pfeiffer, Johan Almenberg, Brad Wilson, Yiling Chen, Brian A Nosek, Magnus Johannesson, and Anna Dreber. Predicting replication outcomes in the many labs 2 study. Journal of Economic Psychology, 2018.

Ben Greiner. Subject pool recruitment procedures: organizing experiments with orsee. Journal of the Economic Science Association, 1(1):114-125, 2015.

Matthew Groh, Nandini Krishnan, David McKenzie, and Tara Vishwanath. The impact of soft skills training on female youth employment: Evidence from a randomized experiment in Jordan. IZA Journal of Labor \& Development, 5(1):9, 2016.

Matthias Heinz, Sabrina Jeworrek, Vanessa Mertins, Heiner Schumacher, and Matthias Sutter. Measuring indirect effects of unfair employer behavior on worker productivity-a field experiment. CESifo Working Paper Series No. 6760, 2017.

Anya Samek and Chuck Longfield. Do Thank-You Calls Increase Charitable Giving? Expert Forecasts and Field Experimental Evidence. Working paper, 2019.

Michael Sanders, Freddie Mitchell, and Aisling Ni Chonaire. Just Common Sense? How well do experts and lay-people do at predicting the findings of Behavioural Science Experiments. 2015.

Joel Slemrod. Tax compliance and enforcement. (24799):1-95, 2018.

Erik Snowberg, Justin Wolfers, and Eric Zitzewitz. Partisan impacts on the economy: Evidence from prediction markets and close elections. The Quarterly Journal of Economics, 122(2):807829, 2007.

Robert L. Winkler and Allan H. Murphy. "Good" probability assessors. Journal of applied Meteorology, 7(5):751-758, 1968.

Justin Wolfers and Eric Zitzewitz. Prediction markets. Journal of economic perspectives, 18(2): 107-126, 2004.

Justin Wolfers and Eric Zitzewitz. Interpreting prediction market prices as probabilities. National Bureau of Economic Research, 2006. 


\section{Appendices}

\section{A Results}

\begin{tabular}{|c|c|c|c|c|c|c|}
\hline \multirow{2}{*}{ Treatment } & \multicolumn{3}{|c|}{ Response rate } & \multicolumn{3}{|c|}{ Registration rate } \\
\hline & Mean & $\mathrm{SE}$ & $95 \% \mathrm{CI}$ & Mean & $\mathrm{SE}$ & $95 \% \mathrm{CI}$ \\
\hline O1 Original letter (Benchmark) & 38 & - & - & 5.1 & - & - \\
\hline \multicolumn{7}{|c|}{$1^{\text {st }}$ round } \\
\hline T1 Control & 44.79 & 0.88 & $43.04-46.53$ & 7.69 & 0.59 & $6.52-8.87$ \\
\hline $\mathrm{T} 2 W h y$ & 45.56 & 0.89 & $43.80-47.32$ & 8.01 & 0.62 & $6.78-9.24$ \\
\hline T3 Exchange & 45.70 & 0.88 & $43.96-47.44$ & 8.10 & 0.62 & $6.86-9.33$ \\
\hline T4 Participation & 45.46 & 0.93 & $43.61-47.31$ & 7.77 & 0.62 & $6.53-9.01$ \\
\hline T5 Deterrence & 48.46 & 0.98 & $46.52-50.40$ & 9.98 & 0.67 & $8.66-11.31$ \\
\hline T6 Norm & 45.14 & 0.93 & $43.28-46.99$ & 8.07 & 0.64 & $6.81-9.34$ \\
\hline \multicolumn{7}{|c|}{$2^{\text {nd }}$ round } \\
\hline T1 Control & 43.77 & 0.73 & $42.32-45.23$ & 7.60 & 0.58 & $6.45-8.74$ \\
\hline $\mathrm{T} 2$ Why & 44.05 & 0.75 & $42.55-45.55$ & 7.74 & 0.61 & $6.52-8.96$ \\
\hline T3 Exchange & 44.13 & 0.76 & $42.62-45.64$ & 7.79 & 0.60 & 6.59-8.99 \\
\hline T4 Participation & 44.04 & 0.79 & $42.48-45.61$ & 7.88 & 0.62 & $6.65-9.10$ \\
\hline T5 Deterrence & 46.21 & 0.81 & $44.59-47.82$ & 9.11 & 0.63 & $7.85-10.36$ \\
\hline T6 Norm & 42.69 & 0.77 & $41.16-44.23$ & 7.44 & 0.62 & $6.22-8.67$ \\
\hline
\end{tabular}

Table 1: Forecasts - Czech Republic.

\begin{tabular}{|l|ccc|ccc|}
\hline \multirow{2}{*}{ Treatment } & \multicolumn{3}{|c|}{ Response rate } & \multicolumn{3}{c|}{ Registration rate } \\
\cline { 2 - 8 } & Mean & SE & $95 \%$ CI & Mean & SE & $95 \%$ CI \\
\hline \hline A1 Baseline (Benchmark) & 43.10 & - & - & 8.60 & - & - \\
\hline A2 Threat & 45.73 & 0.22 & $45.29-46.16$ & 10.14 & 0.16 & $9.82-10.45$ \\
\hline A3 Info & 44.11 & 0.14 & $43.83-44.40$ & 8.98 & 0.11 & $8.76-9.19$ \\
\hline A4 Info\&3Threat & 45.93 & 0.21 & $45.51-46.36$ & 10.28 & 0.17 & $9.93-10.62$ \\
\hline A5 Moral & 44.13 & 0.17 & $43.78-44.48$ & 9.16 & 0.14 & $8.88-9.45$ \\
\hline A6 MoralEThreat & 45.81 & 0.23 & $45.35-46.27$ & 10.08 & 0.17 & $9.75-10.42$ \\
\hline
\end{tabular}

Table 2: Forecasts - Austria. 


\begin{tabular}{|l|ccc|ccc|}
\hline \multirow{2}{*}{ Treatment } & \multicolumn{3}{|c|}{ Response rate } & \multicolumn{3}{c|}{ Registration rate } \\
\cline { 2 - 8 } & $(1)$ & $(2)$ & $(3)$ & $(1)$ & $(2)$ & $(3)$ \\
\hline \hline O1 Original letter (Benchmark) & - & - & - & $=$ & - & - \\
\hline \multicolumn{5}{|c|}{$1^{\text {st }}$ round } \\
\hline T1 Control & 12.81 & 35 & $62.4 \%$ & 13.11 & 25 & $73.1 \%$ \\
\hline T2 Why & 11.54 & 35 & $62.4 \%$ & 12.53 & 30 & $67.7 \%$ \\
\hline T3 Exchange & 11.44 & 31 & $66.7 \%$ & 12.89 & 27 & $71.0 \%$ \\
\hline T4 Participation & 17.64 & 38 & $59.1 \%$ & 15.12 & 33 & $64.5 \%$ \\
\hline T5 Deterrence & 11.70 & 36 & $61.3 \%$ & 12.80 & 29 & $68.8 \%$ \\
\hline T6 Norm & 12.16 & 31 & $66.7 \%$ & 12.43 & 31 & $66.7 \%$ \\
\hline \multicolumn{2}{|c|}{$2^{\text {nd }}$ round } \\
\hline T1 Control & 13.83 & 36 & $61.3 \%$ & 13.2 & 25 & $73.1 \%$ \\
\hline T2 Why & 12.96 & 37 & $60.2 \%$ & 12.42 & 29 & $68.8 \%$ \\
\hline T3 Exchange & 12.95 & 32 & $65.6 \%$ & 13.16 & 27 & $71.0 \%$ \\
\hline T4 Participation & 19.89 & 36 & $61.3 \%$ & 15.99 & 29 & $68.8 \%$ \\
\hline T5 Deterrence & 13.27 & 33 & $64.5 \%$ & 13.11 & 27 & $71.0 \%$ \\
\hline T6 Norm & 14.61 & 34 & $63.4 \%$ & 13.06 & 30 & $67.7 \%$ \\
\hline
\end{tabular}

Table 3: Wisdom-of-crowds effect - Czech Republic. Column (1) reports the mean absolute error, while Column (2) reports the number of forecasters with a lower absolute error than the mean absolute error and Column (3) reports the wisdom-of-crowds effect, i.e. percentages of forecasters that are outperformed by the mean forecast.

\begin{tabular}{|l|ccc|ccc|}
\hline \multirow{2}{*}{ Treatment } & \multicolumn{3}{|c|}{ Response rate } & \multicolumn{3}{c|}{ Registration rate } \\
\cline { 2 - 8 } & $(1)$ & $(2)$ & $(3)$ & $(1)$ & $(2)$ & $(3)$ \\
\hline \hline A1 Baseline (Benchmark) & - & - & - & - & - & - \\
\hline A2 Threat & 0.72 & 29 & $68.8 \%$ & 0.47 & 29 & $68.8 \%$ \\
\hline A3 Info & 3.41 & 55 & $40.9 \%$ & 0.74 & 39 & $58.1 \%$ \\
\hline A4 Info8 Threat & 3.16 & 46 & $50.5 \%$ & 0.58 & 35 & $62.4 \%$ \\
\hline A5 Moral & 5.31 & 54 & $41.9 \%$ & 0.97 & 42 & $54.8 \%$ \\
\hline A6 Moral8Threat & 3.00 & 49 & $47.3 \%$ & 0.76 & 40 & $57.0 \%$ \\
\hline
\end{tabular}

Table 4: Wisdom-of-crowds effect - Austria. Column (1) reports the mean absolute error, while Column (2) reports the number of forecasters with a lower absolute error than the mean absolute error and Column (3) reports the wisdom-of-crowds effect, i.e. percentages of forecasters that are outperformed by the mean forecast. 


\section{B Letters}

\section{C] Česká televize}

Televizní poplatky

Kavčí hory

14070 Praha 4

www.ceskatelevize.cz

tel.: 251109966

fax: 261132073
Sir/Madam

$<$ Title $><$ Name $><$ Surname $>$

$<$ Address $>$

$<$ ZIP code> <City>

\section{Dear Sir/Madam,}

Do you know that Czech TV broadcasting has a tradition of more than 60 years? Do you know that Ceska Televize offers over 110 hours of programs every day on its six channels? Many of these programs, including 24hour news, are produced by Ceska Televize itself. Do you know, e.g., "Doctor Martin", "Jan Hus", "Labyrint", "Vsechnoparty" or "Dancing with the Stars"? Do you watch "Udalosti, komentare" or did you support the Czech team at the hockey World Championship or EURO 2016 qualification? Without television viewers who contribute regularly to the public service by paying the monthly 135 CZK TV licensing fee as required by law, none of these and hundreds of other programs would be available.

We are sending you this letter because unfortunately your name does not appear in the TV fee database although you are registered as an electricity consumer.

What to do, if ...

... you actually pay TV fees?

In this case, we thank you and apologize for the misunderstanding. It is possible that we have reached you at a different address than the one you are register for. If this is the case, the solution is simple: please send us a filled-in declaration of honor (enclosed with this letter). Alternatively, you can fill in the form online at prohlaseni.tvpoplatky.cz. If you fill in the online form, enter the code <code $>$ and your surname $<$ surname $>$ when signing in. The completed declaration can also be sent by email to cestneprohlaseni@ceskatelevize.cz with the code $<$ code $>$ in the subject.

... you do not pay TV fees?

In this case, it is time to start. If you own or possess a television, you are required by law to pay the fee. A household must pay only one TV fee regardless of the number of TV receivers or addresses it possesses. If you do not own or possess a TV or you are exempted from paying the fees for some reason, please notify us via internet or by letter in the same manner as described in the previous paragraph.

TV licensing fees can be paid easily via Czech Post using SIPO, or you can register as a direct payer at www.tvpoplatky.cz.

If this letter is addressed to a person who is not connected to this residence, please state this fact in the attached declaration or in the online form.

If you have further questions or comments, please call $\mathbf{x x x} \mathbf{x x x} \mathbf{x x x}$ or use the free info line at $\mathbf{x x x} \mathbf{x x x} \mathbf{x x x}$ Both lines are open from $8.00-20.00$ Monday-Friday.

Thank you.

Kind regards,

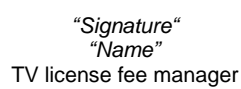

Attachment: Declaration of Honor

Figure 5: Czech Republic - O1 Original letter 


\section{CJ Česká televize}

Televizní poplatky

Kavčí hory

14070 Praha 4

www.ceskatelevize.cz

tel.: 251109966

fax: 261132073
Sir/Madam

$<$ Title $><$ Name $><$ Surname $>$

$<$ Address $>$

$<$ ZIP code $><$ City $>$

Prague, <date >

$<$ code $>$

\section{Explain why you do not pay TV license fees}

Dear Sir/Madam,

Do you have a TV set at home? If yes, your name should appear in the database of TV license fee payers, but we have not been able to find it.

What may have happened?

1) TV fees in your household are paid by somebody else

2) You do not have any TV set or you are exempt from the fee (see page 2 of this letter)

3) You forgot to register

In any case you are required to respond to this letter within $\mathbf{3 0}$ days.

How to respond:

1) Fill in the form on prohlaseni.tvpoplatky.cz (also accessible using QR code). Put <code> into the "addressing code" box.

OR

2) Fill in the attachment to this letter and send it by post or email to the address of CT (detailed instructions can be found in the Answer Sheet).

Do you need help? For further information, read the FAQ on page 2 of this letter. Should you have any other question, please call toll-free $\mathbf{x x x} \mathbf{x x x} \mathbf{x x x}(\mathrm{MO}-\mathrm{FRI}$ 8-16, WED 8-18h), or you can reach us at poplatky@ceskatelevize.cz. We will be happy to answer any questions.

Thank you for your cooperation,

"Signature"

Kind regards,

"Name"

TV license fee manager

Figure 6: Czech Republic - T1 Control letter 
GIS GMBH, 1051 Wien, Postfach 1000

Dear Mr.

Michael Gruber

Linzstraße 1

1100 Wien

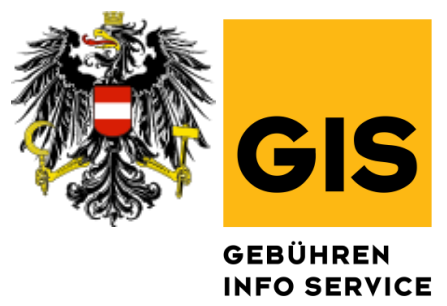

Dear Mr. Michael Gruber,

You listen to radio, you watch TV? Then you are aware of the program variety offered by Austrian Public Broadcasting. The provision of these services, however, requires funding. Therefore, everybody who owns a radio or a TV has to pay license fees. It is the task of GIS Gebühren Info Service $\mathrm{GmbH}$ to ensure that all TV and radio consumers pay these fees.

Our database does not show a registration of TV or radio equipment at your address. This can have several reasons:

- We may have made a mistake in our database and you are already registered at GIS. In this case, we apologize in advance.

- Your registration data may have changed, e.g., due to a move or a name change (marriage), and our computer system cannot match the data with your registration.

- You may not hold a radio or a TV at this address and therefore do not have to register anything.

- Maybe you have just forgotten to register your TV or radio.

We are legally obliged to clarify this issue and kindly ask you to answer our questions - even if you have already registered at GIS. On the back of this letter you will find a response form. Please fill in this form and send it back within the next 14 days.

We thank you for your cooperation. If you require further information, please call our service hotline at 0810001080 (Monday to Friday, 8.00am to 9.00pm, Saturday from 9.00am to 5.00pm) or visit our web page at www.orf-gis.at.

Kind regards,

GIS-Team

Figure 7: Austria - A1 Baseline letter 


\section{Screenshots}
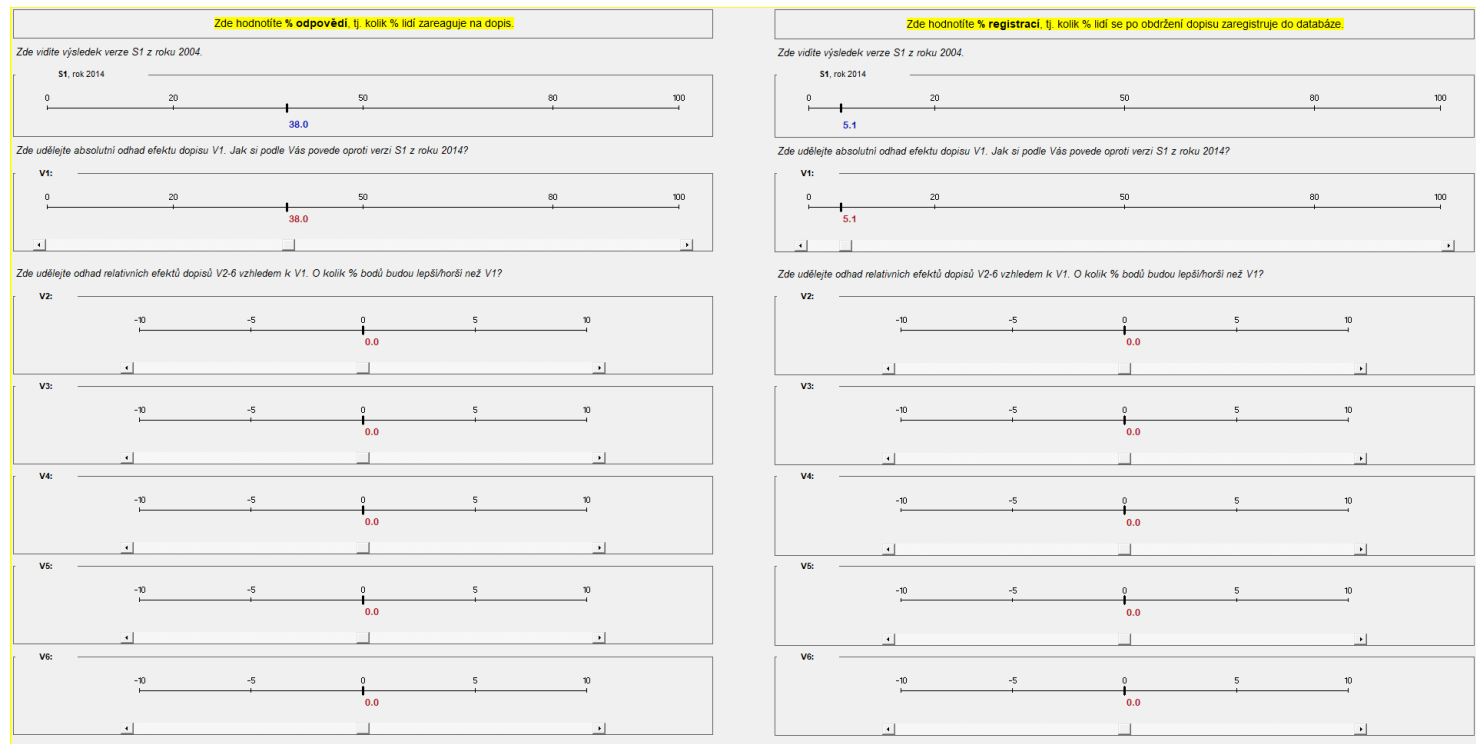

or

Figure 8: Screenshot of the experimental task - Czech Republic
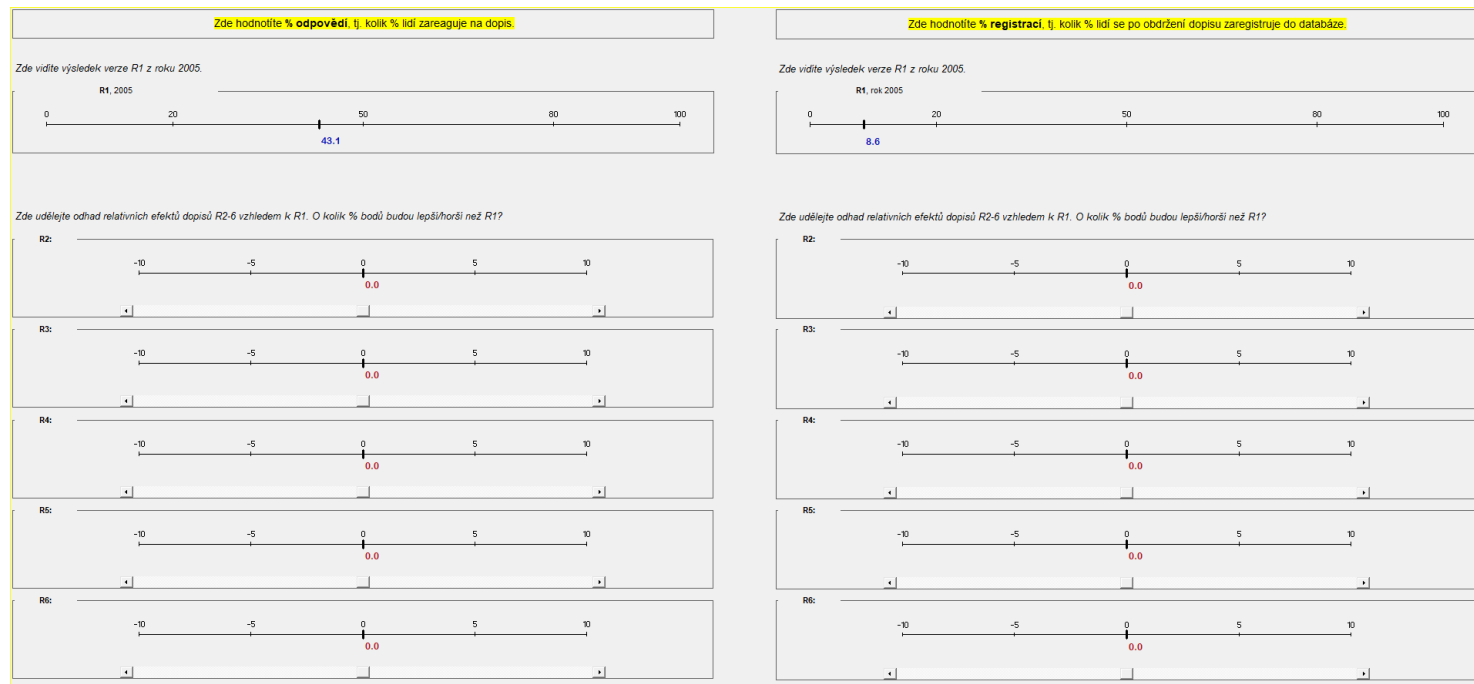

Figure 9: Screenshot of the experimental task - Austria 